\title{
Emergência e desenvolvimento de mudas de fisális sob telas de sombreamento coloridas e pleno sol
}

\author{
Emergence and development of Physalis L. seedlings under colored shade nets and full \\ sunlight
}

\author{
Daniel Fernandes da Silva ${ }^{1}$, Fabíola Villa ${ }^{1^{\star}}$, André Luiz Piva ${ }^{1}$, Elcio Silvério Klosowski ${ }^{1}$, Eder Junior \\ Mezzalira $^{1}$
}

Universidade Estadual do Oeste do Paraná, Cascavel, PR. *Autor para correspondência: fvilla2003@hotmail.com

Submissão: 28/08/2018 / Aceite: 06/03/2020

\begin{abstract}
RESUMO
O presente trabalho teve como objetivo avaliar o efeito das telas de $50 \%$ de sombreamento coloridas sobre a emergência e o desenvolvimento de mudas de três espécies de fisális. $O$ delineamento experimental foi blocos ao acaso, em esquema de parcelas subdivididas com quatro repetições. As telas utilizadas apresentaram $50 \%$ de sombreamento e quatro colorações + cultivo a pleno sol. As subparcelas consistiram de três espécies de fisális. A semeadura foi realizada em tubetes e o desbaste ocorreu 40 dias após a semeadura. Durante este período foram avaliadas algumas variáveis fitotécnicas e fisiológicas. A emergência das plantas foi favorecida em ambiente com presença de telas. Os ambientes de cultivo apresentaram interação com as espécies em relação ao índice de velocidade de emergência, diâmetro do colo, altura das plantas, biomassa seca de folha e na taxa de transpiração das mudas. Os ambientes não interferiram na taxa assimilatória líquida, radiação fotossinteticamente ativa, índice SPAD, biomassa seca de raízes, caule e folhas, e no número de folhas por planta. As telas de sombreamento interferiram na temperatura do ar e umidade relativa do ar e em algumas características fitotécnicas. $O$ uso da tela de sombreamento cor preta proporciou uma muda de melhor qualidade.
\end{abstract}

PALAVRAS-CHAVE: Physalis L., ambiente protegido, Solanaceae, fotossíntese.

\begin{abstract}
The objective of this paper was to evaluate the effect of the $50 \%$ colored shading on the emergence and development of seedlings of three Physalis species. The experimental design used was a completely randomized block design with subdivided plots and four replicates. The treatments consisted of screens providing $50 \%$ shading and four colorations, as well as cultivation in full sunlight. The subplots consisted of three species of Physalis. Seeding was carried out in tubes and thinning was performed 40 days after sowing. During this period, the phytotechnical and physiological variables were evaluated. Plant emergence was favored by the screens. The cultivation environments interacted with the species regarding the emergence speed index, collar diameter, plant height, dry leaf biomass, and seedling transpiration rate. The environments did not interfere with the net assimilation rate, active photosynthetic radiation, SPAD index, dry root, stem and leaf biomass, and number of leaves per plant. The shading screens interfered with the air temperature and relative air humidity, as well as with a few phytotechnical characteristics. The use of a black shading screen provided a higher quality seedling.
\end{abstract}

KEYWORDS: Physalis L., protected environment, Solanaceae, photosynthesis.

\section{INTRODUÇÃO}

O gênero Physalis pertence à família Solanaceae e inclui aproximadamente 100 espécies (LIMA et al. 2010), sendo estas, reconhecidas com facilidade, devido a sua morfologia peculiar, especialmente na frutificação, as quais são caracterizadas pela presença de cálice frutífero (FENG et al. 2018, VILLA et al. 2018). O alto valor nutracêutico e medicinal das espécies deste gênero foram destacadas por HASSANIEN (2011) e BAHMANI et al. (2016) e a utilização de frutos de $P$. peruviana, $P$. angulata e $P$. minima como fonte alimentar foi sugerida por SILVA et al. (2016b), dentre outros fins de uso.

Como se tratam de espécies que podem ser exploradas comercialmente, inclusive por pequenos 
agricultores, a formação de pomares homogêneos depende da utilização de mudas de qualidade. A forma de propagação mais utilizada para a fisális é sexuada (via sementes) (SILVA et al. 2016a). A homogeneidade de germinação das sementes e emergência de plântulas é propiciada por condições adequadas de temperatura, umidade e intensidade luminosa (MUNIZ et al. 2014, CECCO et al. 2018) e tem efeito na qualidade da muda produzida.

As telas de sombreamento constituem uma alternativa para promover redução na amplitude térmica e no total de radiação solar incidente sobre a planta (SILVA et al. 2016b). Desta forma, com modificações ambientais é possível obter incremento produtivo em algumas espécies, principalmente frutíferas, medicinais e ornamentais (CORRÊA et al. 2012, ANJOS et al. 2017).

As telas coloridas são empregadas na produção agrícola objetivando combinar a proteção física com a modificação do espectro luminoso. A coloração preta das telas é considerada neutra, auxiliando apenas na redução da incidência direta da radiação sobre as plantas. A tela de coloração branca semelhante a tela preta não interfere no espectro luminoso, no entanto, pode promover o aumento da temperatura do ambiente. A tela cinza por sua vez gera distribuição da radiação, causada pela refração da luz direta através da malha cinza, bloqueando a radiação infravermelha e aumentando a radiação difusa (HENRIQUE et al. 2011).

Espécies de fisális reagiram de forma diversa quanto ao espectro luminoso na formação de mudas (SILVA et al. 2016b). Ambientes com tela branca propiciaram a formação de mudas de melhor qualidade morfofisiológica na região de Lavras, MG. No entanto, para a cultura do tomateiro, telas de cor vermelha, cinza, preta e aluminizada não promoveram diferenças significativas na altura, diâmetro do colo e massa seca de raízes das mudas (SILVA et al. 2013).

A redução da incidência de radiação solar direta sobre as mudas constitui uma opção sustentável para otimizar a produção. Diante do exposto, objetivou-se com o presente trabalho avaliar o efeito das telas de sombreamento coloridas e cultivo a pleno sol sobre a emergência de plântulas e o desenvolvimento de mudas de espécies de fisális.

\section{MATERIAL E MÉTODOS}

O local da experimentação encontra-se na região oeste do Paraná, sob as coordenadas geográficas

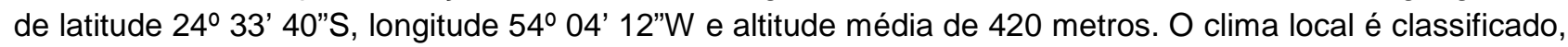
segundo Köppen, como Cfa, clima subtropical com temperatura média do mês mais frio inferior a $18^{\circ} \mathrm{C}$ (mesotérmico) e temperatura média do mês mais quente superior a $22{ }^{\circ} \mathrm{C}$ (ALVARES et al. 2013). Os verões são quentes, geadas pouco frequentes e tendência de concentração das chuvas nos meses de verão, contudo sem estação seca definida. A média anual de precipitação pluvial varia de 1600 a $1800 \mathrm{~mm}$ (CAVIGLIONE et al. 2000).

O experimento foi implantado em delineamento em blocos casualizados, esquema de parcela subdivididas $5 \times 3$, contendo quatro repetições. Os tratamentos dispostos na parcela consistiram das telas com $50 \%$ de sombreamento de colorações branca, cinza, preta e verde e cultivo a pleno sol. As subparcelas foram constituídas de três espécies de fisális (Physalis angulata, $P$. peruviana e P. pubescens). A unidade experimental foi constituída de 32 tubetes de formato cônico $\left(120 \mathrm{~cm}^{3}\right)$, totalizando 60 unidades experimentais. O substrato utilizado foi constituído pela mistura de solo [horizonte A - LATOSSOLO VERMELHO Eutroférrico com textura argilosa] + areia de textura fina + composto orgânico (2:1:1, v:v:v).

A semeadura foi feita a uma profundidade de $0,5 \mathrm{~cm}$ na data de 01 de agosto de 2014, alocando três sementes por tubete. Após ser realizado o processo de semeadura as bandejas com tubetes foram dispostas em ambientes protegidos nas coberturas e lateralmente (área de $1 \mathrm{~m}^{2}$ e altura de $1 \mathrm{~m}$ com telas de sombreamento $(50 \%)$ nas colorações branca, cinza, preta e verde. A produção de mudas também foi realizada em cultivo a pleno sol. Aos 40 dias após a semeadura (DAS) realizou-se o desbaste, mantendo-se uma planta por tubete (CECCO et al. 2018).

A temperatura e umidade relativa do ar observada em cada ambiente foram registradas por sensores automáticos e armazenadas em dataloggers a cada 60 minutos. A irrigação foi realizada por rega manual duas vezes ao dia, aplicando uma lâmina que variou de 1,3 a 3,6 mm. A evapotranspiração de cultura foi estimada com base no coeficiente de cultura $(\mathrm{kc})$ e na evapotranspiração de referência estimada pelo método de Camargo (CAMARGO et al. 1999). Para a fase de produção de mudas utilizou-se o kc de 0,5 recomendado para a cultura do tomateiro (DUARTE et al. 2010).

A evapotranspiração de referência estimada pelo método de Camargo pode ser obtida pela equação: $E T_{0}=R_{T}$. $T$. $k_{f}$. ND, em que: $E T_{0}$ : evapotranspiração de referência $\left(\mathrm{mm} \mathrm{d}^{-1}\right)$; $R_{\mathrm{T}}$ : irradiação solar global extraterrestre ( $\mathrm{mm} \mathrm{d}^{-1}$ de evapotranspiração equivalente); $\mathrm{T}$ : temperatura do ar média $\left({ }^{\circ} \mathrm{C}\right)$ no período 
considerado; $\mathrm{k}_{\mathrm{f}}$ : fator de ajuste que varia com a temperatura do ar média anual do local $\left(\mathrm{k}_{\mathrm{f}}=0,01\right.$ para $\mathrm{T}<23^{\circ} \mathrm{C} ; \mathrm{k}_{\mathrm{f}}=0,0105$, para $\mathrm{T}=24^{\circ} \mathrm{C} ; \mathrm{k}_{\mathrm{f}}=0,011$, para $\mathrm{T}=25^{\circ} \mathrm{C} ; \mathrm{k}_{\mathrm{f}}=0,0115$, para $\mathrm{T}=26^{\circ} \mathrm{C} ;$ e $\mathrm{k}_{f}=0,012$, para $\mathrm{T}>26^{\circ} \mathrm{C}$ ) e ND: número de dias do período considerado.

A emergência de plântulas foi avaliada até os 40 DAS, de forma a calcular o índice de velocidade de emergência (IVE) e a emergência total. As contagens de emergência foram realizadas a cada dia por 60 dias, sendo considerada emergida a plântula cujo caulículo estava acima do nível do substrato. Com base na contagem de emergência, calculou-se o índice de velocidade de emergência (MAGUIRE 1962). Aos 75 DAS foram avaliadas as trocas gasosas, com utilização de medidor portátil de fotossíntese (IRGA, modelo Li-6400XT, Lincon, Nebrasca, USA). As medidas foram realizadas em folhas totalmente expandidas, no período das 15 as 16 horas, e na ausência de nebulosidade.

Foram medidas a taxa assimilatória líquida $(A)$, taxa de transpiração $(E)$, condutância estomática $(g s)$ e radiação fotossinteticamente ativa (RAF). A eficiência do uso da água (EUA) representa a relação entre a taxa assimilatória líquida e transpiração $(\mathrm{A} / E)$. A eficiência intrínseca do uso da água (EUIA) representa a relação entre a taxa assimilatória líquida e condutância estomática $(A / g s)$. Em folhas expostas de quatro plantas escolhidas ao acaso, foi determinado o índice SPAD a partir de medidas do medidor de clorofila portátil SPAD-502.

Aos 75 DAS, data em que se realizou o transplantio foi coletada ao acaso uma amostra de cinco plantas. Destas plantas foi determinado o número de folhas por contagem manual. A altura das plantas com auxílio de régua graduada. O diâmetro de caule cujas medidas foram tomadas a $1 \mathrm{~cm}$ do solo com auxílio de paquímetro digital.

Após estas avaliações a parte aérea das plantas foi separada do sistema radicular. As raízes foram lavadas em água corrente para eliminação de partículas do substrato. A massa seca da parte aérea e raízes (g) foram obtidas a partir de secagem em estufa de ar forçado a $65^{\circ} \mathrm{C}$ por $72 \mathrm{~h}$. Com os dados obtidos, pode ser realizado através de cálculos matemáticos a obtenção da relação entre biomassa seca de parte aérea e raízes. Os dados foram submetidos à análise de variância e, quando significativo, foram submetidos ao teste de Tukey a 5\% de probabilidade de erro, utilizando o software Sisvar (FERREIRA 2011).

\section{RESULTADOS E DISCUSSÃO}

As médias de temperatura do $\operatorname{ar}\left({ }^{\circ} \mathrm{C}\right)$ e umidade relativa do ar (\%) são apresentadas nas Figuras 1 a e 1b. Os resultados apresentados indicam que as telas de sombreamento modificaram a temperatura e umidade relativa do ar nos ambientes. Na Figura 1a verifica-se que a utilização de tela preta na proteção do ambiente proporcionou redução na temperatura do ar entre 9 e $21 \mathrm{~h}$ em relação às demais telas utilizadas. Em relação ao cultivo a pleno sol, a redução na temperatura observada no ambiente com tela preta ocorreu a partir de $11 \mathrm{~h}$ e foi em média de $4 \stackrel{\circ}{\mathrm{C}}$. Neste tipo de ambiente, também se observou menor amplitude térmica. Como alternativa para minimizar os efeitos da temperatura e luminosidade excessivas, empregamse telas, onde o tipo e percentual de sombreamento mais adequado, conforme a espécie, dependerá das condições climáticas locais (SEABRA JÚNIOR et al. 2012).

Das $21 \mathrm{~h}$ até as $6 \mathrm{~h}$ não foram observadas diferenças acentuadas na temperatura do ar entre os ambientes. A produção de mudas em ambientes com telas de coloração branca, verde e preta pode se constituir de alternativa de proteção para perdas de ondas longas observadas em noites, com possibilidade de ocorrência de geadas. A umidade relativa do ar registrada em cultivo a pleno sol foi em média $7 \%$ menor que a do ambiente protegido com tela preta, o que se justifica pela relação inversa que o clima apresenta com a temperatura do ar (Figura 1b).

Na Tabela 1 verificam-se os resultados para emergência de plântulas e significância separadamente para as espécies de fisális e para os ambientes de cultivo. Nota-se que, a tela preta se sobressaiu das demais. A tela preta não altera o espectro luminoso, no entanto, reduz a incidência de radiação direta sobre as plantas (HENRIQUE et al. 2011).

Como se observa nas Figuras 1a e 1b, a tela preta promove, também, redução na temperatura do ar com aumento da umidade relativa do ar. Estes elementos associados à ocorrência de ventos definem a demanda atmosférica por vapor d'água.

A menor percentagem de germinação foi encontrada para cultivo a pleno sol. Neste ambiente se espera maior demanda atmosférica por vapor d'água e, como consequência, maior evaporação. Dentre as espécies estudadas, a maior percentagem de germinação foi encontrada para $P$. angulata. Esta diferença significativa entre as espécies se deve a característica de cada genótipo e a origem das sementes. 
Tabela 1. Emergência de plântulas de espécies de fisális, com 75 DAS cultivadas sob telas de $50 \%$ de sombreamento de diferentes cores e a pleno sol. Marechal Cândido Rondon, PR.

Table 1. Emergence of Physalis seedlings, with 75 DAS cultivated under $50 \%$ shading screens of different colors and in full sunlight. Marechal Cândido Rondon, PR.

\begin{tabular}{ll}
\hline Ambientes de cultivo & Emergência de plântulas (\%) \\
\hline Tela branca & $74,75 \mathrm{~b}^{*}$ \\
Tela cinza & $75,08 \mathrm{ab}$ \\
Tela preta & $79,25 \mathrm{a}$ \\
Tela verde & $76,92 \mathrm{ab}$ \\
Pleno sol & $66,25 \mathrm{c}$ \\
\hline Espécies de fisális & \\
\hline Physalis angulata & $83,70 \mathrm{a}$ \\
Physalis peruviana & $66,70 \mathrm{c}$ \\
Physalis pubescens & $72,95 \mathrm{~b}$ \\
\hline CV (\%) parcela & 14,07 \\
\hline CV (\%) subparcela & 15,24
\end{tabular}

${ }^{*}$ Médias seguidas pela mesma letra diferem entre si estatisticamente na coluna, pelo teste de Tukey, a $5 \%$ de probabilidade de erro.
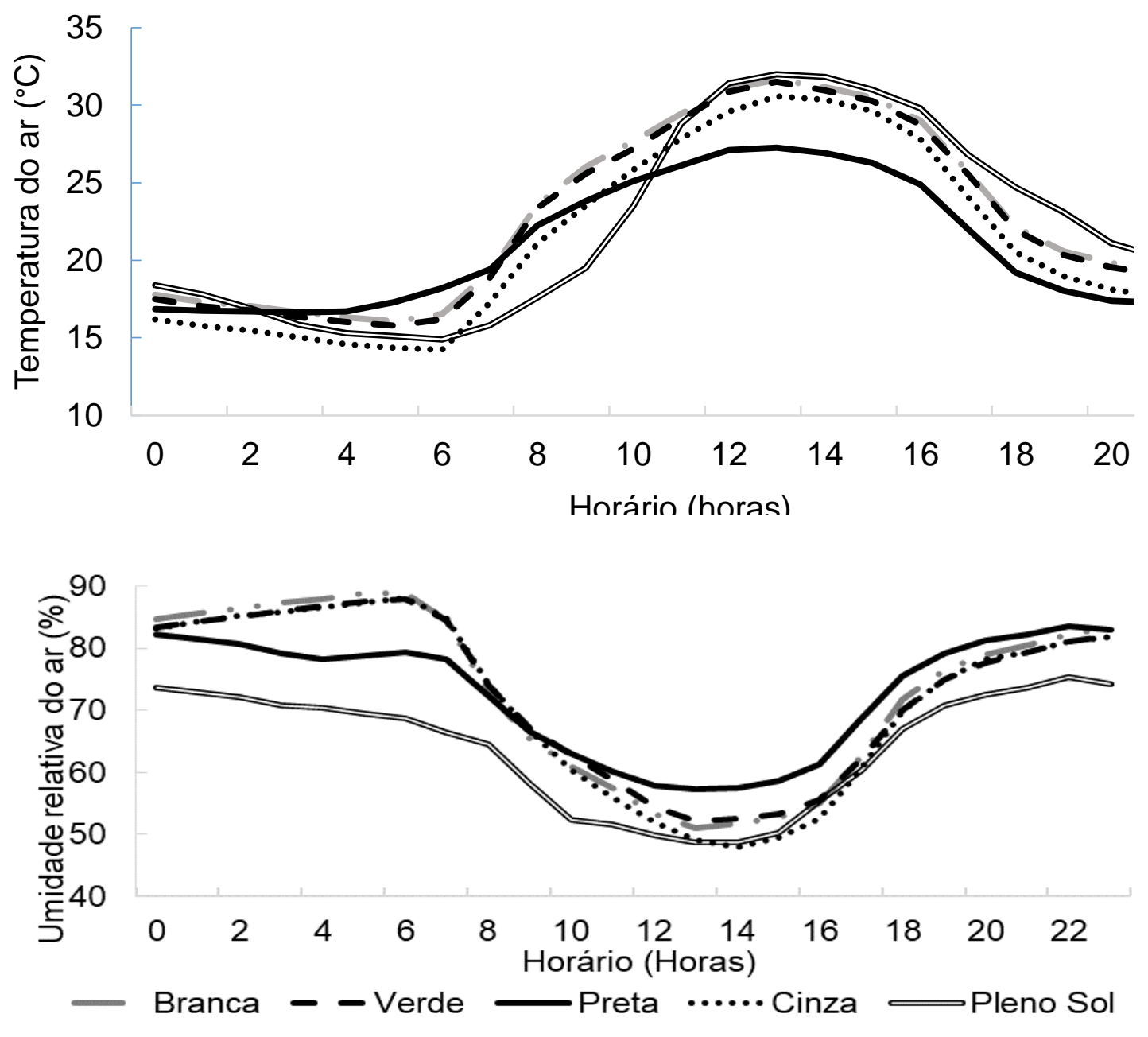

Figuras 1a e 1b. Temperatura e umidade relativa do ar em ambientes protegidos com tela de $50 \%$ de sombreamento coloridas e cultivo a pleno sol na emergência e desenvolvimento inicial de espécies de fisális. Marechal Cândido Rondon, PR.

Figures $1 \mathrm{a}$ and $1 \mathrm{~b}$. Air temperature and relative humidity in protected environments with $50 \%$ colored shading screens and cultivation in full sunlight in the emergency and initial development of Physalis. Marechal Cândido Rondon, PR. 
A diminuição da saturação do ar promove maior perda de água do solo para a atmosfera, e essa diminuição pode estar diretamente relacionada a presença de vento. Este, juntamente com altas temperaturas, tende a provocar a diminuição da umidade do ar no ambiente (OLIVEIRA et al. 2012), fatores determinantes na germinação. A utilização da tela preta no período de germinação e emergência melhorou as condições ambientais para que as sementes desempenhassem seu potencial germinativo.

$\mathrm{Na}$ Tabela 2 verificam-se os resultados para o índice de velocidade de plântulas, com interação significativa entre as espécies e o ambiente de cultivo. Para mudas de $P$. angulata e $P$. pubescens, 0 sombreamento com telas preta e branca resultaram em maior IVE. Para todas as espécies o menor IVE foi para mudas produzidas a pleno sol, não tendo sido observada diferença estatística entre as telas de sombreamento.

Tabela 2. Índice de velocidade de emergência de plântulas de espécies de fisális, com 75 DAS cultivadas sob telas de $50 \%$ de sombreamento de diferentes cores e a pleno sol. Marechal Cândido Rondon, PR.

Table 2. Seedling emergence speed index of Physalis, with 75 DAS cultivated under $50 \%$ shading screens of different colors and full sunlight. Marechal Cândido Rondon, PR.

\begin{tabular}{lllll}
\hline \multicolumn{4}{l}{ Índice de velocidade de emergência (IVE) } \\
\hline Ambientes \\
de cultivo & \multicolumn{2}{l}{ Espécies de fisális } & \multirow{2}{*}{ Médias } \\
\cline { 2 - 4 } & $P$. angulata & P. peruviana & P. pubescens & \\
\hline Branca & $4,64 \mathrm{abA}^{*}$ & $2,54 \mathrm{aC}$ & $3,14 \mathrm{aB}$ & 3,44 \\
Cinza & $4,39 \mathrm{bA}$ & $2,71 \mathrm{aC}$ & $3,04 \mathrm{abB}$ & 3,38 \\
Preta & $4,88 \mathrm{aA}$ & $2,71 \mathrm{aC}$ & $3,40 \mathrm{aB}$ & 3,67 \\
Verde & $3,62 \mathrm{cA}$ & $2,53 \mathrm{aC}$ & $3,24 \mathrm{aB}$ & 3,13 \\
Pleno Sol & $3,03 \mathrm{dA}$ & $2,16 \mathrm{bB}$ & $2,77 \mathrm{bA}$ & 2,65 \\
\hline Médias & 4,11 & 2,53 & 3,12 & \\
\hline CV $(\%)$ & parcela: 14,32 & & subparcela: 16,58 & \\
\hline
\end{tabular}

${ }^{\star}$ Médias seguidas pela mesma letra minúscula na coluna e maiúscula na linha não diferem entre si pelo teste de Tukey, a $5 \%$ de probabilidade de erro.

O resultado inferior obtido para o IVE de sementes das espécies de fisális ocorreu a pleno sol. Tal fato pode ser explicado pela maior perda de água do substrato quando comparado aos tratamentos com presença de telas de sombreamento, independentemente da cor, em função da radiação solar incidente diretamente sobre ele. A presença de tela de sombreamento ajuda na manutenção da umidade relativa do ambiente por dificultar a ventilação (OLIVEIRA et al. 2012). Desta forma a presença das telas pode reduzir a perda de água do substrato para o ambiente permitindo maiores taxas de embebição da semente, acelerando a germinação.

Os resultados para a altura de plantas, diâmetro de colo e número de folhas podem ser visualizados na Tabela 3, verificando-se interação significativa apenas para o diâmetro do colo das plântulas de fisális. As telas de distintas colorações, bem como o cultivo a pleno sol não promoveram diferenças no diâmetro do colo de mudas de fisális da espécie $P$. angulata. A produção de mudas em tela cinza e verde propiciou maior diâmetro do colo para a P. peruviana e em tela branca para P. pubescens.

O diâmetro do colo é um fator importante que se refere à sustentação da planta, favorecendo maior transporte da seiva via xilema, relacionado ao crescimento em altura (ASSIS et al. 2014). De acordo com estes autores, plantas de maior altura, cujo crescimento não é acompanhado pelo aumento do diâmetro do colo, pode indicar algum desequilíbrio na intensidade luminosa fornecida, acarretando estiolamento.

Entretanto, como se verifica na Tabela 3, mesmo havendo diferenças significativas no diâmetro do colo, não há diferenças significativas para altura e número de folhas, sugerindo adequada intensidade luminosa nos ambientes de cultivo para produção de mudas das espécies de fisális. Esses resultados corroboram SILVA et al. (2016b), os quais comprovam que a utilização de malhas coloridas não influenciou no comprimento das plântulas de $P$. peruviana e $P$. pubescens aos 50 DAS.

As plantas podem apresentar incremento na altura, sempre que expostas a condições favoráveis de desenvolvimento, geralmente isso ocorre quando a planta apresenta aumento na produção fotossintética. Em alguns casos o alongamento dos órgãos pode ser confundido com o incremento em altura. $O$ alongamento, no entanto, está muitas vezes relacionado com a baixa intensidade luminosa. Por outro lado, a alta intensidade luminosa ocasionada pela exposição a pleno sol pode gerar danos aos tecidos fotossintetizantes das plantas, acarretando menores taxas de desenvolvimento, que quando cultivadas em 
ambiente protegido (SANTOS et al. 2010).

Tabela 3. Altura de plantas, diâmetro do colo e número de folhas de espécies de fisális, com 75 DAS cultivadas sob telas de $50 \%$ de sombreamento de diferentes cores e a pleno sol. Marechal Cândido Rondon, PR.

Table 3. Plant height, collar diameter, and number of leaves of Physalis, with 75 DAS cultivated under screens of $50 \%$ of shading of different colors and full sunlight. Marechal Cândido Rondon, PR.

\begin{tabular}{|c|c|c|c|c|}
\hline \multicolumn{4}{|c|}{ Altura de plantas $(\mathrm{cm})$} & \multirow{3}{*}{ Médias } \\
\hline \multirow{2}{*}{$\begin{array}{l}\text { Ambientes } \\
\text { de cultivo }\end{array}$} & \multicolumn{3}{|c|}{ Espécies de fisális } & \\
\hline & P. angulata & P. peruviana & P. pubescens & \\
\hline Branca & $10,66^{\text {n.s. }}$ & $10,38^{\text {n.s. }}$ & $10,43^{\text {n.s. }}$ & 10,49 \\
\hline Cinza & $10,38^{\text {n.s. }}$ & $10,28^{\text {n.s. }}$ & $10,42^{\text {n.s. }}$ & 10,36 \\
\hline Preta & $10,04^{\text {n.s. }}$ & $9,84^{\text {n.s. }}$ & $10,16^{\text {n.s. }}$ & 10,01 \\
\hline Verde & $10,31^{\text {n.s. }}$ & $9,69^{\text {n.s. }}$ & $10,11^{\text {n.s. }}$ & 10,04 \\
\hline Pleno Sol & $10,98^{\text {n.s. }}$ & $9,99^{\text {n.s. }}$ & $9,89^{\text {n.s. }}$ & 10,03 \\
\hline Médias & 10,32 & 10,03 & 10,20 & \\
\hline CV (\%) & parcela: 16,98 & & subparcela: 19,88 & \\
\hline \multicolumn{5}{|c|}{ Diâmetro de colo $(\mathrm{mm})$} \\
\hline Branca & $2,63 a A^{*}$ & $2,81 a b A$ & $3,12 \mathrm{aA}$ & 2,85 \\
\hline Cinza & $2,29 \mathrm{aB}$ & $3,37 \mathrm{aA}$ & $2,14 \mathrm{bB}$ & 2,60 \\
\hline Preta & 2,15 aA & $2,46 \mathrm{bA}$ & $2,31 \mathrm{bA}$ & 2,31 \\
\hline Verde & $2,43 \mathrm{aB}$ & 3,25 aA & $1,89 \mathrm{bB}$ & 2,52 \\
\hline Pleno Sol & $2,16 \mathrm{aB}$ & $3,19 a b A$ & $2,07 \mathrm{bB}$ & 2,47 \\
\hline Médias & 2,33 & 3,02 & 2,30 & \\
\hline CV (\%) & parcela: 11,74 & & subparcela: 15,37 & \\
\hline \multicolumn{5}{|c|}{ Número de folhas } \\
\hline Branca & $15,25^{\text {n.s. }}$ & $14,50^{\text {n.s. }}$ & $14,00^{\text {n.s. }}$ & 14,58 \\
\hline Cinza & $14,83^{\text {n.s. }}$ & $13,75^{\text {n.s. }}$ & $15,42^{\text {n.s. }}$ & 14,67 \\
\hline Preta & $13,75^{\text {n.s. }}$ & $13,75^{\text {n.s. }}$ & $13,50^{\text {n.s. }}$ & 13,67 \\
\hline Verde & $13,50^{\text {n.s. }}$ & $13,50^{\text {n.s. }}$ & $15,75^{\text {n.s. }}$ & 14,25 \\
\hline Pleno Sol & $14,00^{\text {n.s. }}$ & $14,75^{\text {n.s. }}$ & $14,25^{\text {n.s. }}$ & 14,33 \\
\hline Médias & 14,27 & 14,05 & 14,58 & \\
\hline CV (\%) & parcela: 18,68 & & subparcela: 13,18 & \\
\hline
\end{tabular}

*Médias seguidas pela mesma letra minúscula na coluna e maiúscula na linha não diferem entre si pelo teste de Tukey, a $5 \%$ de probabilidade de erro. ${ }^{\text {n.s. }}=$ não significativo.

Em relação a biomassa seca (Tabela 4) não foi verificada interação significativa entre os ambientes de cultivo e as espécies. A biomassa seca de folhas (BSF) e a biomassa seca média de folhas (BSMF) foram maiores para $P$. angulata e $P$. pubescens. A $P$. peruviana obteve menores valores, pois apresenta folhas de menor tamanho, acarretando menor biomassa que as outras espécies.

A maior BSPA de mudas sob telas preta e cinza se devem à BSMF. Esta, por sua vez, depende do número de folhas por muda. Nos ambientes protegidos com estas telas se observa em grande parte do dia, menores temperaturas do ar (Figura 1a) em relação aos demais ambientes, com consequência fisiológica no balanço de carbono das plantas. Em geral, em plantas expostas à temperatura do ar elevada, a fotossíntese decresce ao passo que, processos de respiração e foto-respiração aumentam, afetando a biomassa do vegetal como um todo (MEZZALIRA et al. 2017).

O incremento na produção de BSMF pode estar relacionado a boa relação vermelho/vermelho distante das telas. Plantas heliófilas por serem plantas que apresentam bom desenvolvimento em ambientes com bastante iluminação utilizam com eficácia as altas intensidades luminosas, devido à alta capacidade de transporte de elétrons, gerando assim maiores ganhos fotossintéticos (SILVA et al. 2018).

Para biomassa seca de caule e raízes não se verificou efeito significativo para os fatores estudados (Tabela 4). Nas condições experimentais, e aos 75 DAS as plantas apresentaram parte aérea e raízes semelhantes, independentemente do ambiente de cultivo. O mesmo foi observado para biomassa seca de raízes de tomateiro, em estudo realizado com o objetivo de avaliar as malhas coloridas na produção de mudas (SILVA et al. 2013). Esse resultado observado no experimento pode ser explicado pela utilização de substrato homogêneo e com boa disponibilidade hídrica, favorecendo o desenvolvimento radicular, independente da espécie. 
Tabela 4. Biomassa seca de folhas (BSF), biomassa seca média de folhas (BSMF), biomassa seca de caule (BSC), biomassa seca de raízes (BSR) e biomassa de parte aérea (BSPA) de mudas de três espécies de fisális, aos 75 dias após a semeadura, cultivadas sob telas de $50 \%$ de sombreamento de diferentes cores e a pleno sol. Marechal Cândido Rondon, PR.

Table 4. Dry leaf biomass (BSF), average dry leaf biomass (BSMF), dry stem biomass (BSC), dry root biomass (BSR), and shoot biomass (BSPA) of three Physalis species at 75 days after sowing, grown under $50 \%$ shading of different colors and full sunlight. Marechal Cândido Rondon, PR.

\begin{tabular}{cccccc}
\hline Ambientes de cultivo & $\mathrm{BSF}(\mathrm{g})$ & $\mathrm{BSMF}(\mathrm{mg})$ & $\mathrm{BSC}(\mathrm{g})$ & $\mathrm{BSR}(\mathrm{g})$ & $\mathrm{BSPA}(\mathrm{g})$ \\
\hline Branca & $0,23^{\text {n.s. }}$ & $22,07 \mathrm{a}^{*}$ & $0,19^{\text {n.s. }}$ & $0,24^{\text {n.s. }}$ & $0,42 \mathrm{ab}$ \\
Cinza & $0,25^{\text {n.s. }}$ & $20,00 \mathrm{ab}$ & $0,20^{\text {n.s. }}$ & $0,26^{\text {n.s. }}$ & $0,45 \mathrm{a}$ \\
Preta & $0,25^{\text {n.s. }}$ & $16,78 \mathrm{~b}$ & $0,22^{\text {n.s. }}$ & $0,25^{\text {n.s. }}$ & $0,47 \mathrm{a}$ \\
Verde & $0,25^{\text {n.s. }}$ & $17,07 \mathrm{~b}$ & $0,20^{\text {n.s. }}$ & $0,22^{\text {n.s. }}$ & $0,45 \mathrm{ab}$ \\
Pleno Sol & $0,23^{\text {n.s. }}$ & $19,04 \mathrm{ab}$ & $0,17^{\text {n.s. }}$ & $0,25^{\text {n.s. }}$ & $0,40 \mathrm{~b}$ \\
\hline Espécies & $\mathrm{BSF}(\mathrm{g})$ & $\mathrm{BSMF}(\mathrm{mg})$ & $\mathrm{BSC}(\mathrm{g})$ & $\mathrm{BSR}(\mathrm{g})$ & $\mathrm{BSPA}(\mathrm{g})$ \\
\hline P. angulata & $0,27 \mathrm{a}^{*}$ & $19,75 \mathrm{a}$ & $0,18^{\text {n.s. }}$ & $0,25^{\text {n.s. }}$ & $0,45^{\text {n.s. }}$ \\
P. peruviana & $0,25 \mathrm{~b}$ & $17,08 \mathrm{~b}$ & $0,20^{\text {n.s. }}$ & $0,22^{\text {n.s. }}$ & $0,45^{\text {n.s. }}$ \\
P. pubescens & $0,30 \mathrm{a}$ & $20,15 \mathrm{a}$ & $0,16^{\text {n.s. }}$ & $0,26^{\text {n.s. }}$ & $0,46^{\text {n.s. }}$ \\
\hline CV $(\%)$ parcela & 25,70 & 14,04 & 26,00 & 17,32 & 15,24 \\
\hline CV $(\%)$ subparcela & 20,56 & 16,75 & 37,95 & 32,11 & 21,82 \\
\hline
\end{tabular}

${ }^{*}$ Médias seguidas pela mesma letra na coluna não diferem entre si pelo teste de Tukey, a 5\% de probabilidade de erro. n.s. $=$ não significativo.

Outra característica importante no desenvolvimento de espécies vegetais é a fotossíntese e a quantidade de clorofila presente (TAIZ \& ZERGER 2013). Neste caso, a utilização de leituras com o SPAD, possibilitam chegar a uma relação aceitável dos teores de clorofila extraíveis de Physalis (MOURA et al. 2016). Quando utilizado o medidor portátil de clorofila (SPAD-502), não fora verificada significância para os ambientes de cultivo (Tabela 5), ou seja, o uso de telas não interferiu na concentração de clorofila nas folhas das espécies durante a experimentação.

Tabela 5. Índice SPAD, taxa assimilatória líquida $(A)$, taxa de transpiração $(E)$ e densidade de fluxo de fótons fotossinteticamente ativos (DFFF) de mudas de três espécies de fisális, com 75 dias após a semeadura, cultivadas sob telas de $50 \%$ de sombreamento de diferentes cores e a pleno sol. Marechal Cândido Rondon, PR.

Table 5. SPAD index, net assimilation rate $(A)$, transpiration rate $(E)$, and photosynthetically active photon flux density (DFFF) of the seedlings of three Physalis species 75 days after sowing, cultivated under screens of $50 \%$ shading of different colors and full sunlight. Marechal Cândido Rondon, PR.

\begin{tabular}{lccc}
\hline Ambiente de cultivo & SPAD & $A$ & $\left.E\left[\mathrm{mmol}^{\mathrm{n}} \mathrm{H}_{2} \mathrm{O}\right) \mathrm{m}^{-2} \mathrm{~s}^{-1}\right]$ \\
\hline Branca & $0,13^{\text {n.s. }}$ & $11,89^{\text {n.s. }}$ & $7,55 \mathrm{ab}^{*}$ \\
Cinza & $0,13^{\text {n.s. }}$ & $10,59^{\text {n.s. }}$ & $6,30 \mathrm{~b}$ \\
Preta & $0,13^{\text {n.s. }}$ & $11,47^{\text {n.s. }}$ & $7,80 \mathrm{ab}$ \\
Verde & $0,12^{\text {n.s. }}$ & $11,48^{\text {n.s. }}$ & $6,75 \mathrm{~b}$ \\
Pleno Sol & $0,13^{\text {n.s. }}$ & $14,60^{\text {n.s. }}$ & $9,41 \mathrm{a}$ \\
\hline Espécies de fisális & & & \\
\hline P. angulata & $0,13^{\text {n.s. }}$ & $11,59^{\text {n.s. }}$ & $7,36^{\text {n.s. }}$ \\
P. peruviana & $0,12^{\text {n.s. }}$ & $12,03^{\text {n.s. }}$ & $7,40^{\text {n.s. }}$ \\
P. pubescens & $0,14^{\text {n.s. }}$ & $12,41^{\text {n.s. }}$ & $7,92^{\text {n.s. }}$ \\
\hline CV (\%) parcela & $17,19^{\text {n.s. }}$ & $27,26^{\text {n.s. }}$ & $21,68^{\text {n.s. }}$ \\
\hline CV $(\%)$ subparcela & $25,30^{\text {n.s. }}$ & $20,93^{\text {n.s. }}$ & $23,28^{\text {n.s. }}$ \\
\hline
\end{tabular}

${ }^{*}$ Médias seguidas pela mesma letra minúscula na coluna e maiúscula na linha não diferem entre si pelo teste de Tukey, a $5 \%$ de probabilidade de erro. ${ }^{\text {n.s. }}=$ não significativo.

Os ambientes de cultivo também não apresentaram efeito significativo sobre a taxa assimilatória líquida $(A)$, inferindo assim que, no momento da avaliação a assimilação de carbono não foi influenciada pelos ambientes. TAIZ \& ZEIGER (2013) afirmam que o melhor horário para avaliação da fotossíntese é no período das 09:00 as 10:00 horas da manhã, podendo em outros períodos influenciar negativamente os parâmetros avaliados. Como neste estudo, a avaliação foi realizada no período crítico das 15:00 as 16:00 horas da tarde, os resultados podem ter sofrido influência de alguns fatores climáticos, como temperatura e umidade relativa do ar.

Em relação a taxa de transpiração foi possível observar efeito significativo dos ambientes, com maior 
taxa em mudas produzidas a pleno sol. A diferença significativa entre os ambientes está diretamente ligada ao efeito da temperatura e umidade relativa do ar (UR), pois no horário de avaliação, a média de temperatura foi maior nos ambientes com tela branca, preta e cultivo a pleno sol, os mesmos ambientes que apresentavam UR mais baixa. O aumento da radiação solar e temperatura do ar, juntamente com a diminuição da UR influencia diretamente a transpiração (PIVETTA et al. 2011). A conservação da temperatura foliar similar ou ligeiramente abaixo à temperatura do ar demonstra a competência de refrigeração das diversas espécies, via transpiração, visando manter a planta protegida das faixas térmicas elevadas (KRÖBER et al. 2015).

$\mathrm{Na}$ Tabela 6 verificam-se os resultados para a condutância estomática, eficiência no uso da água (EUA) e eficiência intrínseca do uso da água (EIUA), com interação significativa entre ambientes de cultivo e espécies de fisális. A EUA é uma razão entre a taxa de fotossíntese líquida $(A)$ e a taxa de transpiração $(E)$, ao passo que a EIUA se refere à relação entre a $A$ e a gs. Estes parâmetros são apontados como importantes medidas da capacidade das espécies de estabelecerem sobre ambientes com limitação de recursos hídricos (VADEZ et al. 2014).

Tabela 6. Condutância estomática, eficiência no uso da água e eficiência intrínseca do uso da água em mudas de espécies de fisális, com 75 dias após a semeadura, cultivadas sob telas de $50 \%$ de sombreamento e a pleno sol. Marechal Cândido Rondon, PR.

Table 6. Stomatal conductance, water use efficiency, and intrinsic water use efficiency in the seedlings of Physalis species, 75 days after sowing, grown under 50\% shading and full sunlight. Marechal Cândido Rondon, PR.

\begin{tabular}{|c|c|c|c|c|}
\hline \multicolumn{5}{|c|}{ Condutância estomática (gs) $\left(\mathrm{mol}\left(\mathrm{H}_{2} \mathrm{O}\right) \mathrm{m}^{-2} \mathrm{~s}^{-1}\right)$} \\
\hline \multirow{2}{*}{$\begin{array}{l}\text { Ambientes } \\
\text { de cultivo }\end{array}$} & \multicolumn{3}{|c|}{ Espécies de fisális } & \multirow[t]{2}{*}{ Médias } \\
\hline & P. angulata & P. peruviana & P. pubescens & \\
\hline Branca & $0,09 \mathrm{bB}^{*}$ & $0,15 \mathrm{aA}$ & $0,12 \mathrm{aAB}$ & 0,12 \\
\hline Cinza & $0,09 \mathrm{bB}$ & $0,07 \mathrm{cB}$ & $0,12 \mathrm{aA}$ & 0,09 \\
\hline Preta & $0,15 \mathrm{aA}$ & $0,12 a b A$ & $0,12 \mathrm{aA}$ & 0,13 \\
\hline Verde & $0,10 \mathrm{bA}$ & $0,11 \mathrm{bA}$ & $0,10 \mathrm{aA}$ & 0,10 \\
\hline Pleno sol & $0,15 \mathrm{aA}$ & $0,11 \mathrm{bB}$ & $0,12 \mathrm{aB}$ & 0,13 \\
\hline Médias & 0,12 & 0,11 & 0,12 & \\
\hline CV (\%) & parcela: 9,09 & & subparcela: & \\
\hline \multicolumn{5}{|c|}{ Eficiência no uso da água $\left(\mu \mathrm{mol}\left[\mathrm{CO}_{2}\right] \mathrm{mmol}\left[\mathrm{H}_{2} \mathrm{O}\right]^{-1}\right)$} \\
\hline Branca & $1,68 \mathrm{a} A^{*}$ & $1,55 \mathrm{bAB}$ & $1,50 \mathrm{aB}$ & 1,58 \\
\hline Cinza & $1,69 \mathrm{aAB}$ & $1,83 \mathrm{aA}$ & $1,59 \mathrm{aB}$ & 1,70 \\
\hline Preta & $1,38 \mathrm{bA}$ & $1,52 \mathrm{bA}$ & $1,54 \mathrm{aA}$ & 1,48 \\
\hline Verde & $1,68 \mathrm{aA}$ & $1,82 \mathrm{aA}$ & $1,65 \mathrm{aA}$ & 1,72 \\
\hline Pleno Sol & $1,56 a b A$ & $1,52 \mathrm{bA}$ & $1,54 \mathrm{aA}$ & 1,54 \\
\hline Médias & 1,60 & 1,65 & 1,56 & \\
\hline CV (\%) & parcela: 6,86 & & subparcela: & \\
\hline \multicolumn{5}{|c|}{ Eficiência intrínseca do uso da água $\left(\mu \mathrm{mol}\left[\mathrm{CO}_{2}\right] \mathrm{mol}\left[\mathrm{H}_{2} \mathrm{O}\right]^{-1}\right)$} \\
\hline Branca & $113,40 \mathrm{aA}$ & $94,68 \mathrm{bA}$ & $92,58 \mathrm{aA}$ & 100,21 \\
\hline Cinza & $117,65 \mathrm{aA}$ & $130,75 a b A$ & $106,22 \mathrm{aA}$ & 118,21 \\
\hline Preta & $81,17 \mathrm{aA}$ & $90,70 \mathrm{bA}$ & 99,87 aA & 90,58 \\
\hline Verde & $114,03 \mathrm{aA}$ & $98,35 \mathrm{abA}$ & $110,80 \mathrm{aA}$ & 107,73 \\
\hline Pleno Sol & $92,18 \mathrm{aB}$ & $137,32 \mathrm{aA}$ & $127,44 \mathrm{aA}$ & 118,98 \\
\hline Médias & 103,69 & 110,35 & 107,38 & \\
\hline CV (\%) & parcela: 24,8 & & subparcela & \\
\hline
\end{tabular}

${ }^{\star}{ }^{\star}$ Médias seguidas pela mesma letra minúscula na coluna e maiúscula na linha não diferem entre si pelo teste de Tukey, a $5 \%$ de probabilidade de erro.

A condutância estomática de $P$. angulata foi maior quando cultivada sob tela preta e a pleno sol. Para a $P$. peruviana a condutância estomática foi maior sob tela branca e, para $P$. pubescens não se observou diferença entre os ambientes de cultivo. A maior condutância estomática para as espécies está diretamente ligada a taxa de transpiração das mudas, pois quanto maior a abertura dos estômatos, maior é a possibilidade de perda de vapor d'água por transpiração (KRÖBER et al. 2015).

Considerando que, em condições tropicais e subtropicais, muitas vezes o excesso de radiação e temperaturas elevadas são os principais fatores limitantes do crescimento e produtividade de algumas 
culturas (ASTHIR 2015). Do ponto de vista térmico, a tela preta (para as $14 \mathrm{~h}$ ) foi mais eficiente em manter a temperatura abaixo de $30{ }^{\circ} \mathrm{C}$, limite crítico de temperatura do ar para início de efeitos negativos no crescimento de plantas da família Solanaceae. A condutância estomática apresenta uma correlação negativa com a eficiência do uso da água, sendo que, quando ocorre aumento da gs, possibilita maior disponibilidade de água para a atmosfera através da transpiração, diminuindo assim a eficiência do uso de água.

A eficiência no uso da água (EUA) para a $P$. angulata foi maior quando cultivada sob tela branca, verde e cinza. Para a $P$. peruviana a EUA foi maior sob tela cinza e verde. Para a $P$. pubescens não se observou diferença significativa entre os ambientes de cultivo. Esses maiores valores de EUA nos ambientes com tela branca, verde e cinza estão relacionados a menor taxa de transpiração observada nestes ambientes, pois a taxa de transpiração apresenta correlação negativa com a eficiência do uso da água, ou seja, quando diminui a taxa de transpiração ocorre o aumento da EUA.

No presente trabalho pode-se verificar para $P$. peruviana e $P$. angulata, a ocorrência de eventos fisiológicos diretamente ligados, como o aumento na taxa de transpiração, aumento da taxa de assimilação líquida e condutância estomática, e diminuição do EUA. Quanto maior a abertura estomática, maior a perda de água para a atmosfera e maior diminuição da eficiência do uso da água. No entanto, há um aumento da assimilação de carbono. Durante o período experimental, foram observados 23 dias que ocorreram precipitação. Levando em consideração a radiação solar, observou-se que no período houve 60 dias com nebulosidade. Os valores verificados para o período podem explicar a não ocorrência de efeitos dos ambientes para algumas variáveis.

As telas coloridas, por sua capacidade de alterar o espectro de radiação transmitida, podem formar um novo elemento no cultivo protegido. Quando viveiristas escolhem um telado, quase $100 \%$ fazem uso de tela preta, com cerca de $50 \%$ de sombreamento. A escolha pelo preto, até então se deu pela força do uso, por se ponderar que, além de causar o sombreamento, apresenta propriedades que aprimoram as condições microclimáticas do ambiente.

Com base nos parâmetros avaliados, nas condições climáticas do período e da necessidade de se aprimorar o manejo tecnológico da produção de mudas de boa qualidade, perante o comportamento vegetativo apresentado neste trabalho, surge como alternativa para os produtores, realizar a utilização de telas na produção de mudas de espécies de fisális, principalmente a preta. De modo geral, para que que se produza uma muda de qualidade, o diâmetro do colo, altura das plântulas, número de folhas e volume de sistema radicular destas devem estar relacionados.

\section{CONCLUSÃO}

As telas de sombreamento interferiram na temperatura do ar e umidade relativa do ar e em algumas características das espécies de fisális, como emergência, índice de velocidade de emergência, diâmetro do colo, biomassa seca de parte aérea e trocas gasosas.

O uso de ambiente protegido com tela de sombreamento cor preta proporcionou para as espécies de fisális uma muda de melhor qualidade, devido melhor resposta para IVE, emergência total de plântulas e menor relação entre parte aérea e raízes.

\section{REFERÊNCIAS}

ANJOS GL et al. 2017. Initial growth of sweet pepper in different substrates and light environments. Científica 45: 406413.

ALVARES CA et al. 2013. Köppen's climate classification map for Brazil. Meteorologische Zeitschrift 22: 711-728.

ASTHIR B. 2015. Protective mechanisms of heat tolerance in crop plants. Journal of Plant Interactions 10: 22-29.

ASSIS GA et al. 2014. Correlação entre crescimento e produtividade do cafeeiro em função do regime hídrico e densidade de plantio. Bioscience Journal 30: 666-676.

BAHMANI M et al. 2016. Physalis alkekengi: a review of its therapeutic effects. Journal of Chemical and Pharmaceutical Sciences 9: 1472-1475.

CAMARGO AP et al. 1999. Ajuste da equação de Thornthwaite para estimar a evapotranspiração potencial em climas áridos e superúmidos, com base na amplitude térmica diária. Revista Brasileira de Agrometeorologia 7: 251-257.

CAVIGLIONE JH et al. 2000. Cartas climáticas do Paraná. Londrina: IAPAR. 1 CD-ROM.

CECCO RM et al. 2018. Germinação e crescimento inicial de mudas de espécies não convencionais de fisális em diferentes substratos e ambientes. Revista de Ciências Agroveterinárias 17: 45-53.

CORRÊA RM et al. 2012. Crescimento de plantas, teor e qualidade de óleo essencial de folhas de orégano sob malhas coloridas. Global Science and Technology 5: 11-22.

DUARTE GRB et al. 2010. Medida e estimativa da evapotranspiração do tomateiro cultivado sob adubação orgânica em ambiente protegido. Semina: Ciências Agrárias 31: 563-574. 
FENG S et al. 2018. Molecular identification of species of Physalis (Solanaceae) using a candidate DNA barcode: the chloroplast psbA-trnH intergenic region. Genome 61: 15-20.

FERREIRA DF. 2011. Sisvar: a computer statistical analysis system. Ciência \& Agrotecnologia 35: 1039-1042.

HASSANIEN MFR. 2011. Physalis peruviana: a rich source of bioactive phytochemicals for functional foods and pharmaceuticals. Journal of Food Reviews International 27: 259-273.

HENRIQUE PC et al. 2011. Aspectos fisiológicos do desenvolvimento de mudas de café cultivadas sob telas de diferentes colorações. Pesquisa Agropecuária Brasileira 46: 458-465.

KRÖBER W et al. 2015. Relating stomatal conductance to leaf functional traits. Journal of visualized experiments 104 : 100-107.

LIMA CSM et al. 2010. Sistemas de tutoramento e épocas de transplantio de physalis. Ciência Rural 40: $2472-2479$.

MAGUIRE JD. 1962. Speed of germination aid in selection and evaluation for seeding emergence and vigor. Crop Science 2: 176-177.

MEZZALIRA EJ et al. 2017. Desenvolvimento inicial de espécies de fisális submetidas a ambientes de cultivo. Revista de Ciências Agroveterinárias 16: 293-301.

MOURA PHA et al. 2016. Cobertura plástica e densidade de plantio na qualidade das frutas de Physalis peruviana L. Revista Ceres 63: 334-339.

MUNIZ JK et al. 2014. General aspects of physalis cultivation. Ciência Rural 44: 964-970.

OLIVEIRA GM et al. 2012. Temperatura do ar no interior e exterior de ambientes protegidos. Revista Verde de Agroecologia e Desenvolvimento Sustentável 7: 250-257.

PIVETTA CR et al. 2011. Evapotranspiração máxima do tomateiro sob estufa plástica em função de variáveis fenométricas e meteorológicas. Bragantia 70: 707-714.

SANTOS LL et al. 2010. Luminosidade, temperatura do ar e do solo em ambientes de cultivo protegido. Revista de Ciências Agro-Ambientais 8: 83-93.

SEABRA JÚNIOR SN et al. 2012. Cultivo de alface em Cáceres MT: perspectivas e desafios. Revista Conexão 8: 130137.

SILVA DF et al. 2018. Productive and qualitative parameters of of Physalis species cultivated under colored shade nets. Revista Brasileira de Fruticultura 40: e-528.

SILVA DF et al. 2013. Conservação pós-colheita de fisális e desempenho produtivo em condições edafoclimáticas de Minas Gerais. Revista Ceres 60: 826-832.

SILVA DF et al. 2016a. The production of Physalis spp. seedlings grown under different colored shade nets. Acta Scientiarum 38: 257-263.

SILVA DF et al. 2016b. Light spectrum on the quality of fruits of physalis species in subtropical area. Bragantia 75: 371 376.

TAIZ L \& ZEIGER E. 2013. Fisiologia vegetal. 5.ed. Porto Alegre: Artmed. 954 p.

VADEZ V et al. 2014. Transpiration efficiency: new insights into an old story. Journal of Experimental Botany 65: 61416153.

VILLA F et al. 2018. Initial development of Physalis seedlings in substrates and containers. Comunicata Scientiae 9: 50 57. 